\title{
Screening and In-Vitro Analysis of Lactobacillus reuteri Strains for Short Chain Fatty Acids Production, Stability and Therapeutic Potentials in Colorectal Cancer
}

\author{
Kahouli I1,2, Malhotra M1, Tomaro-Duchesneau C1, Saha S1,5, Marinescu D1, Rodes LS 1 , Alaoui-Jamali MA ${ }^{3,4}$ and Prakash S1,2* \\ ${ }^{1}$ Biomedical Technology and Cell Therapy Research Laboratory-Departments of Biomedical Engineering, Physiology, and Artificial Cells and Organs Research Center. \\ Faculty of Medicine, McGill University, 3775 University Street, Montreal, Quebec, H3A 2B4, Canada \\ ${ }^{2}$ Department of Experimental Medicine, Faculty of Medicine, McGill University, 1110 Pine Avenue West, Montreal, Quebec, H3A 1A3, Canada \\ ${ }^{3}$ Departments of Medicine and Oncology, Faculty of Medicine, McGill University, Gerald Bronfman Centre, Room 210, 546 Pine Avenue West, Montreal, Quebec, H2W \\ 1S6, Canada \\ ${ }^{4}$ Lady Davis Institute for Medical Research and Segal Cancer Centre, Sir Mortimer B. Davis-Jewish General Hospital, 3755 Côte Ste-Catherine Road, Montreal, Quebec, \\ H3T 1E2, Canada \\ ${ }^{5}$ Faculty of Dentistry, McGill University, 640 University Street, Montreal, Quebec, H3A 0C7, Canada
}

\begin{abstract}
The use of probiotics as preventive agents in colorectal cancer is widely reported in the literature. However, the bioactivity of specific bacterial strains is only partially understood. Here, we identified Lactobacillus reuteri strains with anti-proliferative activity against colorectal cancer cells. We investigated the bioavailability and the efficacy of short chain fatty acids secreted by distinct Lactobacillus reuteri strains on the inhibition of colorectal cancer cells growth. Five $L$. reuteri strains were screened based on the short chain fatty acids bio-production and anti-proliferative effects on Caco-2 colon cancer cells. The composition of probiotic short chain fatty acids in cell culture conditioned medium was used to prepare short chain fatty acid synthetic formulations that were compared with the $L$. reuteri cell culture conditioned media. Later, the bio-stability of the bacteria in a simulated intestinal fluid was determined. Results showed that the production of short chain fatty acids was strain-dependent. L. reuteri NCIMB $-11951,-701359$ and -702656 were the most potent in producing total short chain fatty acids $(402.2 \pm 23.5, p<0.05$ compared with the rest of strains) and inhibiting Caco-2 (by $56.7 \pm 1.6 \%$ compared to untreated cells at $72 \mathrm{~h}, p<0.001$ ). Comparing the inhibitory effect of the probiotic cell culture conditioned medium and the corresponding short chain fatty acid synthetic formulation showed that the role and relevance of short chain fatty acid production in colorectal cancer cell growth suppression was strain-dependent. L. reuteri NCIMB -702656 and -701359 showed resistance in simulated intestinal fluid (104.6 $\pm 0.6 \%$ and $105.7 \pm 4.1 \%$ of viability at $4 \mathrm{~h}$, respectively) and produced high amounts of total short chain fatty acids $(1245.49 \pm 0.49-1391.58 \pm 4.84 \mathrm{mg} / \mathrm{L}$ at $24 \mathrm{~h}$, respectively). Depending partly on short chain fatty acid bio-production, specific $L$. reuteri strains demonstrated growth inhibitory activity and may be considered as a potential chemopreventive agent against colorectal cancer.
\end{abstract}

Keywords: Biotherapeutic; Probiotics; Colorectal cancer; Short chain fatty acids, Cell proliferation, Intestinal fluid

\begin{abstract}
Abbreviations: CRC: colorectal cancer; SCFA: short chain fatty acid; GI: gastrointestinal; L.: Lactobacillus; LAB: Lactic acid bacteria; IBD: Inflammatory bowel disease; UC: Ulcerative colitis; SIF: Simulated intestinal fluid; LA: Lactic acid; AA: Acetic acid; PA: Propionic acid; BA: Butyric acid; CFU: Colony-forming unit; OD: Optical density; CM: Conditioned cell culture medium; TNF: Tumor necrosis factor; $L$. reuteri-CM: Conditioned cell culture medium of $L$. reuteri bacteria. L. a 314: L. acidophilus ATCC 314; L. r 11951: L. reuteri NCIMB 11951; L. $r$ 701089: L. reuteri NCIMB 701089; L. $r$ 701359: L. reuteri NCIMB 701359; L. r 702655: L. reuteri NCIMB 702655; L. r 702656: L. reuteri NCIMB 702656
\end{abstract}

\section{Introduction}

Colorectal cancer (CRC) is among the leading causes of cancer mortality worldwide, yet dietary intervention represents a valuable approach to prevent CRC development, particularly in susceptible human populations $[1,2]$. Several chemopreventive and biotherapeutic approaches have been reported for the prevention of CRC and other gut conditions [3,4]. Individuals with inherent gene defects that predispose to CRC, inflammatory bowel disease (IBD) and ulcerative colitis (UC) have been suggested to benefit from the consumption of probiotics. Millions of healthy people and patients with such conditions, who are at high risk of CRC, consumes probiotics as neutraceutical products
$[5,6]$. Probiotics, defined as beneficial bacteria, have been proposed to balance disturbed gastrointestinal (GI) microflora and dysfunctions of the human GI tract [7]. Lactic acid bacteria (LAB) are predominantly reported to excrete components with protective properties against colon cancer causing-factors. They can release anti-carcinogenic compounds and, promote balanced bacterial growth in the colon to produce greater quantities of short chain fatty acids (SCFAs) such as acetate, propionate and butyrate, all which have anti-cancer properties [8]. Although several studies have reported the anti-proliferative or pro-apoptotic effect of probiotic bacteria on colon carcinoma cells [9$11]$, no systemic studies have been reported that screen or characterize

*Corresponding author: Prakash S, Biomedical Technology and Cell Therapy Research Laboratory-Departments of Biomedical Engineering, Physiology, and Artificial Cells and Organs Research Center. Faculty of Medicine, McGill University, 3775 University Street, Montreal, Quebec, H3A 2B4, Canada, Tel: +1-514-3983676; Fax: +1-514-398-7461; E-mail: satya.prakash@mcgill.ca

Received November 27, 2014; Accepted December 22, 2014; Published December 28, 2014

Citation: Kahouli I, Malhotra M, Tomaro-Duchesneau C, Saha S, Marinescu D, et al. (2015) Screening and In-Vitro Analysis of Lactobacillus reuteri Strains for Short Chain Fatty Acids Production, Stability and Therapeutic Potentials in Colorectal Cancer. J Bioequiv Availab 7: 039-050. doi:10.4172/jbb.1000212

Copyright: ( 2015 Kahouli I, et al. This is an open-access article distributed under the terms of the Creative Commons Attribution License, which permits unrestricted use, distribution, and reproduction in any medium, provided the original author and source are credited. 
Citation: Kahouli I, Malhotra M, Tomaro-Duchesneau C, Saha S, Marinescu D, et al. (2015) Screening and In-Vitro Analysis of Lactobacillus reuteri Strains for Short Chain Fatty Acids Production, Stability and Therapeutic Potentials in Colorectal Cancer. J Bioequiv Availab 7: $039-050$. doi:10.4172/jbb.1000212

certain LAB as potential candidates for CRC biotherapies such as $L$. reuteri bacteria, investigated for anti-pathogenic activity and capacity to produce conjugated linoleic acid [12-15]. L. reuteri is prominent among the Lactobacillus population in the GI ecosystem [16], and has been widely reported to be beneficial for some GI conditions such as $\mathrm{UC}$, which is a strong risk indicator for CRC [17]. Other cases included constipation [18], diarrhea [19], maintaining mucosal barrier [20] and colon motility [21]. The biological activity of $L$. reuteri has been shown to be mediated in part by the production lactic acid and bacteriocins, which potentially influence the commensal micro-organisms [22, 23] and reduce intestinal absorption of endogenous and exogenous carcinogens [15]. According to the most current probiotic selection criteria, these bacteria have to stay active, withstand the intestinal environment and exert beneficial effects, once reaching the intestines.

The goal of this study was to screen five strains of $L$. reuteri, for Human epithelial CRC production of SCFAs and to assess their antiproliferative effects of these SCFAs on colon cancer cells. Then, for the most potent candidates, the stability of the probiotic bacteria and the bioproduction of lactic, acetic, propionic and butyric acids in a simulated intestinal fluid (SIF) were investigated. Within this study, to determine why $L$. reuteri bacteria suppressed colon cancer cells in-vitro, the role of SCFAs was simulated and a correlation between colon cancer cell growth inhibition and the concentrations of naturally produced SCFAs was established. Later, concentrations of SCFAs similar to the ones produced by $L$. reuteri bacteria were tested separately in formulations on colon cancer cells. For each $L$. reuteri strains, the SCFAs produced were quantified and those numbers were used to prepare similar SCFA synthetic formulations. If a SCFA synthetic formulation was found to inhibit cancer cells less than the corresponding $L$. reuteri $\mathrm{CM}$, then this will show that the SCFAs may not be the only anti-cancer compounds produced by the bacteria and that there are probably other bacterial molecules excreted with anti-proliferative activity against colon cancer cells. However, if the SCFA synthetic formulation suppressed colon cancer cells equally or more than the $L$. reuteri bacteria then this would suggest that the levels of SCFAs of $L$. reuteri bacteria were mostly responsible for the anti-proliferative effect.

\section{Materials and Methods}

\section{Materials}

De Man, Rogosa, Sharpe (MRS) broth and agar were obtained from Fisher Scientific (Ottawa, ON, Canada). Eagle's Minimum Essential Medium (EMEM), Dulbecco's Modified Eagle's Medium (DMEM), phosphate-buffered saline (PBS) and fetal bovine serum (FBS) were purchased from Invitrogen. Water was purified with an EasyPure reverse osmosis system and a NanoPure Diamond Life Science (UV/ UF) ultrapure water system from Barnstead (Dubuque, IA, USA). Sodium L-Lactate, propionate, acetate, and butyrate were purchased from Sigma (St. Louis, MO, USA).

Bacterial cells: The bacterial strain of L. acidophilus ATCC 314 was purchased from Cedarlane Laboratories (Burlington, ON, Canada) and used as a positive control and for comparative purposes. Five $L$. reuteri strains: (L. reuteri NCIMB -11951, -701359, -701089, -702655, and -702656) were purchased from the National Collection of Industrial and Marine Bacteria (NCIMB, Aberdeen, Scotland, UK). Bacterial cultures were maintained by continuous in MRS media at $1 \%(\mathrm{v} / \mathrm{v})$ and growth was monitored by both OD at a wavelength of $620 \mathrm{~nm}$ (Perkin Elmer 1420 Multilabel Counter, USA) and colony counting.

Mammalian cells: Human epithelial colorectal cancer Mammalian cells: Human epithelial colorectal cancer: Human epithelial colorectal cancer adenocarcinoma cell line Caco-2 (HTB37) was obtained from American Type Culture Collection (ATCC, Manassas, VA). Cells were maintained in Eagle's Minimum Essential Medium (EMEM) supplemented with $20 \%$ of fetal bovine serum (FBS). Cells were incubated in a $\mathrm{CO}_{2}$ incubator at $37^{\circ} \mathrm{C}$ in air supplemented with $5 \% \mathrm{CO}_{2}$ for about two weeks till fully differentiated. For proliferation assays, all cells were left to attach for 24-48 h in 96-well plates before experiments, till they reached $50-60 \%$ confluence. At this point, cell medium was replaced by probiotic conditioned medium (CM) diluted with serum/antibiotic-free DMEM.

Preparation of probiotic treatments: The probiotic conditioned medium (CM), a bacterial cell free extract, was prepared with slight modifications from protocols adapted from Grabig et al. [24] and Kim et al., [25]. First, L. reuteri and L. acidophilus bacteria were incubated in Lactobacillus MRS broth at $37^{\circ} \mathrm{C}$ in air supplemented with $5 \%$ $\mathrm{CO}_{2}$ for $24 \mathrm{~h}$ and subcultured three times at $1 \%(\mathrm{v} / \mathrm{v})$. At the third passage, the bacteria were incubated at $37^{\circ} \mathrm{C}$ to reach late exponential phase (14-16 h). Second, the bacteria were precipitated from the MRS medium by centrifugation $\left(1000 \mathrm{x} \mathrm{g}, 15 \mathrm{~min}, 4^{\circ} \mathrm{C}\right)$ and washed twice with PBS. Finally, the probiotic conditioned cell culture medium $(\mathrm{CM})$ was produced by incubating washed probiotic cells $\left(10^{7}-10^{9} \mathrm{cfu} /\right.$ $\mathrm{mL}$ ) in DMEM cell culture medium at $37^{\circ} \mathrm{C}$ for $2 \mathrm{~h}$. The medium was centrifuged twice $\left(1000 \mathrm{x} \mathrm{g}, 15 \mathrm{~min}, 4^{\circ} \mathrm{C}\right)$ and then sterile-filtered $(0.2$ $\mu \mathrm{M}$-pore-size filter, Millipore). Prior to the treatment on the colon cancer cells, the probiotic $\mathrm{CM}$ of each bacterium was mixed with fresh DMEM at a ratio of 1:2 and the $\mathrm{pH}$ was adjusted to 7 using $2 \mathrm{M} \mathrm{NaOH}$ and $2 \mathrm{M} \mathrm{HCl}$.

Quantification of lactic acid and SCFAs: SCFAs produced by the L. reuteri strains were measured during the growth of bacteria in SIF and after the preparation of the corresponding probiotic CM. SCFAs were separated using a HPLC method adapted from Dubey and Mistry, with modifications [26,27]. A Model 1050 UV HPLC system (HewlettPackard HP1050 series, Agilent Technologies, USA), equipped with a UV-vis detector and diode array detector (DAD) set at $210 \pm 5 \mathrm{~nm}$, was used. $100 \mu$ l of sample was injected through an autosampler. A prepacked Rezex ROA-organic acid H+ (8\%) (150 x $7.80 \mathrm{~mm}$, Phenomenex, Torrance, CA, USA) fitted with an ion- exclusion microguard refill cartridge was used. Data were acquired using ChemStation supported with LC3D software Rev A.03.02 (Agilent Technologies, CO, USA). The mobile phase (A) $0.05 \mathrm{M} \mathrm{H}_{2} \mathrm{SO}_{4}$ (very polar) and the mobile phase (B) of acetonitrile (2\%) were used with an isocratic gradient pumped at a flow rate of $0.7-0.8 \mathrm{~mL} / \mathrm{min}$, through a column heated to $35^{\circ} \mathrm{C}$. Lactic, acetic, propionic, and butyric acids were used to prepare a standard solution at concentrations of $1,10,100,500,1000 \mathrm{ppm}$ (in triplicate) to generate the standard curve. The amounts of SCFAs were calculated using the linear regression equations $\left(R_{2} \geq 0.99\right)$ from the corresponding standard curves.

Assessment of cancer cell proliferation: The proliferation of colon cancer cells treated with the probiotic treatments was evaluated using an ATP bioluminescence assay (CellTiter-Glo Luminescent Cell Viability Assay, Promega, USA). Caco-2 cells were seeded into 96-well culture plates at $5 \times 10^{3}$ cells per well and stabilized for $24 \mathrm{~h}$ $\left(37^{\circ} \mathrm{C}, 5 \% \mathrm{CO}_{2}\right)$. After exposure to L. reuteri probiotic treatments for $24 \mathrm{~h}, 48 \mathrm{~h}$, and $72 \mathrm{~h}$, cell viability was determined following the guidelines from the manufacturer [28]. After incubating the cells with the probiotic treatment, the plate and its contents were equilibrated at room temperature (RT) for approximately $30 \mathrm{~min}$. $100 \mathrm{ul}$ of luminescent reagent was added to the an equal volume of the cell culture medium present in each well. The contents of the 96-well plate 
Citation: Kahouli I, Malhotra M, Tomaro-Duchesneau C, Saha S, Marinescu D, et al. (2015) Screening and In-Vitro Analysis of Lactobacillus reuteri Strains for Short Chain Fatty Acids Production, Stability and Therapeutic Potentials in Colorectal Cancer. J Bioequiv Availab 7: 039-050. doi:10.4172/jbb.1000212

were mixed for 2 minutes on an orbital shaker $(200 \mathrm{rpm})$ to induce cell lysis. Afterwards, the plate was allowed to incubate at RT for 10 min to stabilize the luminescent signal, and the data was recorded using a spectrophotometer (Perkin Elmer, Victor 3, multi-label microplate reader, MA, USA)

Preparation of SIF: To determine the potential of L. reuteri bacteria in surviving intestinal conditions, a simulated intestinal fluid (SIF) was prepared as described previously by Qian Zhao et al. [29], with some modifications. In brief, the solution of SIF contained glucose $(5.5 \mathrm{~g} / \mathrm{L})$, yeast extract $(3.5 \mathrm{~g} / \mathrm{L})$, pancreatin $(2 \mathrm{~g} / \mathrm{L})$, oxgall $(1.5 \mathrm{~g} / \mathrm{L})$, pectin $(2$ $\mathrm{g} / \mathrm{L})$, inulin $(0.54 \mathrm{~g} / \mathrm{L})$, fructooligosaccharides $(0.85 \mathrm{~g} / \mathrm{L})$, starch $(3 \mathrm{~g} / \mathrm{L})$ and monobasic potassium phosphate $\left(\mathrm{KH}_{2} \mathrm{PO}_{4}, 3.3 \mathrm{~g} / \mathrm{L}\right)$ dissolved in deionized water. The $\mathrm{pH}$ was adjusted to 6.8 using $2 \mathrm{M} \mathrm{NaOH}$ and $2 \mathrm{M}$ $\mathrm{HCL}$, the solution was autoclaved at $120^{\circ} \mathrm{C}$ for $15 \mathrm{~min}$ and cooled at RT before use.

Determination of Lactobacilli stability in SIF: The bBacterial pellet was separated from a 16-24 h MRS-bacterial culture by centrifugation $\left(1000 \mathrm{xg}, / 10-15 \mathrm{~min}, 4^{\circ} \mathrm{C}\right)$ and washed twice with a $\mathrm{NaCl}$ solution of $0.85 \%(\mathrm{w} / \mathrm{v}) .3 \%$ of the bacterial suspension was used to inoculate $15 \mathrm{~mL}$ of SIF solution, which was sealed and incubated micro-anaerobically. Lactobacillus cultures were incubated for $24 \mathrm{~h}$ in triplicate. At each time point ( $0 \mathrm{~h}, 4 \mathrm{~h}, 8 \mathrm{~h}, 12 \mathrm{~h}, 16 \mathrm{~h}$ and $24 \mathrm{~h}$ ), the bacterial density $\left(\mathrm{OD}_{620} \mathrm{~nm}\right)$ was measured, bacterial viability (colony counting on agar plates) was estimated, a supernatant was filtered (5 $\mathrm{mL}$ of bacterial culture centrifuged and $0.22 \mu \mathrm{m}$ filtered), and stored at $-80^{\circ} \mathrm{C}$ until further use.

Efficacy and role of SCFAs: This method was used to determine the role of the levels of naturally produced SCFAs in the inhibition of colorectal cancer cells, probiotic SCFAs produced by $L$. reuteri bacteria were compared with SCFA synthetic formulations, made at the same concentrations. Thus, the anti-proliferative effect of bioactive compounds, such as lactic acid and the SCFAs (acetic, propionic and butyric acids), produced by Lactobacillus bacteria in different media was measured. The concentrations of SCFAs were determined for each Lactobacillus CM, then formulations containing the same composition in lactic acid and the SCFAs were prepared and added to the culture media of colon cancer cells for $72 \mathrm{~h}$. Viability of the colon cancer cells was determined using an ATP bioluminescence assay. This analysis determined the inhibitory effects of SCFAs on colon cancer growth in comparison with the Lactobacillus cell free extracts.

Statistical analysis: Data are presented as means \pm Standard Error of the Mean (SEM) of replicates. Correlations were determined using Pearson correlation method. Statistical significance was generated for the treated groups as compared with each other by means of the oneway analysis of variances (ANOVA) with the Tukey's comparison test and student's t-test. SPSS statistics software package was used (version 20.0, IBM corporation, New York, NY, USA). $P$-value of $p<0.05$ were considered significant.

\section{Results}

\section{L. reuteri does produce lactic acid in a conditioned cell culture media (CM)}

This experiment was designed to screen these LAB for their ability to produce lactic acid in DMEM media challenged with bacterial cells. As observed in Fig. 1, lactic acid produced by five L. reuteri strains was quantified and the data shows that $L$. reuteri NCIMB $702656(642.5 \pm$ $9.3 \mathrm{mg} / \mathrm{L})$ and $L$. reuteri NCIMB $701359(643.1 \pm 9.3 \mathrm{mg} / \mathrm{L})$ produced significantly higher amounts of lactic acid compared with all strains $(p$ $<0.001$ ), followed by $L$. reuteri NCIMB 1195, which produced $369.1 \pm$ $15.1 \mathrm{mg} / \mathrm{L}$ of lactic acid. It was observed that $L$. reuteri NCIMB 701089 $(208.3 \pm 2.8 \mathrm{mg} / \mathrm{L})$ and L. reuteri NCIMB $702655(233.4 \pm 7.3 \mathrm{mg} / \mathrm{L})$ produced significantly less lactic acid $(p<0.001)$

\section{The production of SCFAs by $L$. reuteri is strain-dependent}

To determine the SCFA bio-production ability of $L$. reuteri bacteria in $\mathrm{CM}$, acetate, propionate, and butyrate produced by the bacteria were

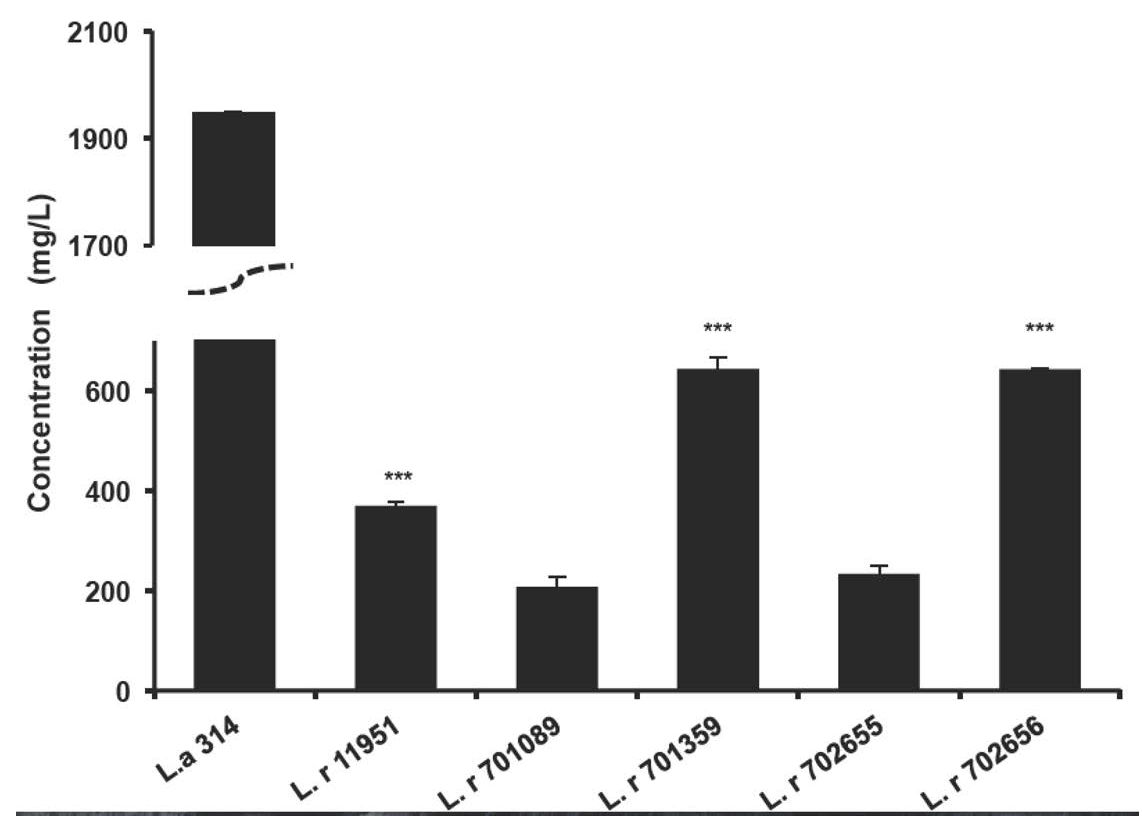

Figure 1: Illustrating the ability of $L$. reuteri strains to produce lactic acid in the cell culture conditioned medium (CM). Lactic acid was produced after incubating bacterial cells of $L$. reuteri NCIMB $-11951,-701089,-701359,-702655$, or -702656 in DMEM cell media $\left(2 \mathrm{~h}, 37^{\circ} \mathrm{C}, 5 \% \mathrm{CO}_{2}\right)$. L. acidophilus ATCC 314 is used as a control. Data are presented as mean \pm SEM $(n=3)$. ${ }^{* t} p<0.001$, compared with L. reuteri NCIMB 701089. 
Citation: Kahouli I, Malhotra M, Tomaro-Duchesneau C, Saha S, Marinescu D, et al. (2015) Screening and In-Vitro Analysis of Lactobacillus reuteri Strains for Short Chain Fatty Acids Production, Stability and Therapeutic Potentials in Colorectal Cancer. J Bioequiv Availab 7: 039-050. doi:10.4172/jbb.1000212

quantified. For acetic acid production (Fig. 2 (a)), the L. reuteri NCIMB $701089(43.4 \pm 3.3 \mathrm{mg} / \mathrm{L})$ produced the least amount of acetic acid, whereas, L. reuteri NCIMB $702656(182.1 \pm 15.4 \mathrm{mg} / \mathrm{L})$ produced the highest amount $(p<0.01)$ followed by L. reuteri NCIMB $11951(131.2$ $\pm 4.8 \mathrm{mg} / \mathrm{L}, p<0.05)$ and then $L$. reuteri NCIMB $701359(116,0 \pm 4$ $\mathrm{mg} / \mathrm{L})$. For the production of propionic acid ((Fig. 2 (b)), L. reuteri NCIMB $701089(38.7 \pm 1.4 \mathrm{mg} / \mathrm{L})$ and L. reuteri NCIMB $702655(45.5$ $\pm 6.4 \mathrm{mg} / \mathrm{L}$ ) produced the least amount among the L. reuteri strains $(p<0.05)$. The highest amount of propionic acid was produced by $L$. reuteri $\mathrm{NCIMB} 702656(161.4 \pm 3 \mathrm{mg} / \mathrm{L}, p<0.01)$ followed by $L$. reuteri NCIMB $11951(111.2 \pm 5.5 \mathrm{mg} / \mathrm{L}, p<0.05)$ and L. reuteri NCIMB $701359(78.5 \pm 10.9 \mathrm{mg} / \mathrm{L}, p<0.05)$. For butyric acid production (Fig. 2 (c)), L. reuteri NCIMB $702656(58.75 \pm 9.1 \mathrm{mg} / \mathrm{L})$ was significantly better than all other bacteria $(p<0.001)$. Moreover, $L$. reuteri NCIMB $11951(28.6 \pm 4 \mathrm{mg} / \mathrm{L})$ and $L$. reuteri NCIMB $701359(27.62 \pm 4.2 \mathrm{mg} / \mathrm{L})$ significantly produced more butyrate compared with $L$. reuteri NCIMB 701089 (no butyrate detected, $p=0.001$ ). Finally, L. reuteri NCIMB 702656 (402.21 $\pm 40.7 \mathrm{mg} / \mathrm{L})$, L. reuteri $\mathrm{NCIMB} 701359$ (222.07 \pm 27 , $04 \mathrm{mg} / \mathrm{L})$, and L. reuteri NCIMB $11951(271,03 \pm 5.2 \mathrm{mg} / \mathrm{L})$ produced significantly more total probiotic SCFAs than $L$. reuteri NCIMB 702655 $(160.87 \pm 20.4 \mathrm{mg} / \mathrm{L}, p<0.001, p=0.0064$ and $p=0.002$, respectively) and L. reuteri NCIMB $701089(82.12 \pm 5.4 \mathrm{mg} / \mathrm{L}, p<0.001$, Fig. $2(\mathrm{c}))$.

\section{Identification of $L$. reuteri strains that supressed colon cancer} cell growth

Screening L. reuteri strains based on the inhibitory effect on Caco-
2 colon cancer cells was performed using the corresponding probiotic $\mathrm{CM}$ at a ratio of $1: 2$ at different time points (Fig. 3). At $24 \mathrm{~h}, 48 \mathrm{~h}$ and 72 $\mathrm{h}$, the luminescence-based cell viability was determined. At $24 \mathrm{~h}$ (Fig. 3 (a)), L. reuteri NCIMB -701359 and -702656 inhibited cancer cell growth by $19.5 \pm 2.22 \%$ and $4.78 \pm 1.3 \%$, compared with the untreated cells, respectively. For 48 h of treatment (Fig. 3 (c)), L. reuteri NCIMB $-11951,-701089,-701359$, and -702656 inhibited colon cancer growth by $32.02 \pm 0.97 \%(p<0.001), 4.71 \pm 0.3 \%(p<0.05), 47.76 \pm 0.69 \%$, $42.78 \pm 1.08 \%(p<0.001)$, respectively, compared with un treated cells. As observed, at $72 \mathrm{~h}$ post treatment (Fig. 2 (c)), the inhibition of colon cancer cells was best achieved with the CM of $L$. reuteri NCIMB 702656 $(56.68 \pm 1.61 \%, p<0.001)$ and $L$. reuteri NCIMB $701359(55.58 \pm 2.18$ $\%, p<0.001)$ compared with $L$. reuteri NCIMB 11951 (42.9 $\pm 3.6 \%, p$ $=0.002, p=0.01$, respectively), and all were significantly higher than $L$. reuteri NCIMB $702655(p<0.001)$ and L. reuteri NCIMB 701089 (6.43 $\pm 0.7 \%, p<0.001)$.

SCFAs produced by $L$. reuteri may be responsible of their inhibitory effect

To verify whether the inhibitory effect of $L$. reuteri bacteria is due to the production of probiotic SCFAs, SCFA synthetic formulations (SSFs) containing acetic, propionic and butyric acids were prepared, as described in Table 1, and tested on Caco-2 cells for $72 \mathrm{~h}$ (Fig. 5). The results showed no significant difference observed in the antiproliferative effects of L. acidophilus ATCC 314 and L. reuteri NCIMB 11951 and their SSFs. For L. reuteri NCIMB 701089 and L. reuteri
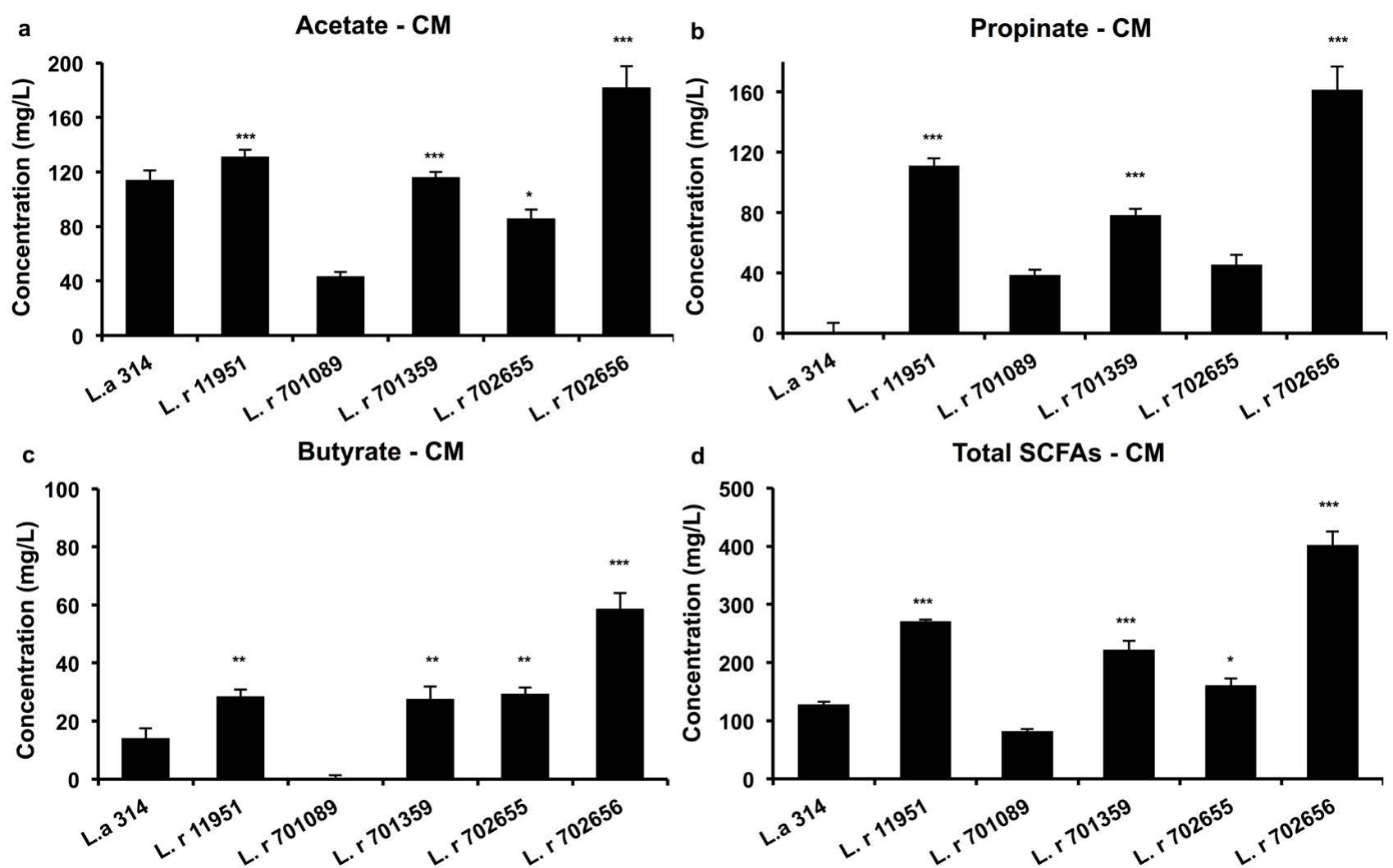

Figure 2: Study of the bio-production of SCFAs by L. reuteri strains in cell culture conditioned medium (CM): In order to establish if $L$. reuteri NCIMB -11951, $-701089,-701359,-702655$, and -702656 , produces SCFAs known as active anti-cancer compounds in-vitro conditions; the active bacterial cells were incubated in DMEM $\left(2 \mathrm{~h}, 37^{\circ} \mathrm{C}, 5 \% \mathrm{CO}_{2}\right)$. Then, the acetic, propionic, and butyric acids were separated and quantified by HPLC method. L. acidophilus ATCC 314 is used as a control. Data are presented as mean \pm SEM $(n=3) .{ }^{*} p<0.05$, ${ }^{* *} p<0.01$ and ${ }^{* * *} p<0.001$, compared with $L$. reuteri NCIMB -701089 . 
Citation: Kahouli I, Malhotra M, Tomaro-Duchesneau C, Saha S, Marinescu D, et al. (2015) Screening and In-Vitro Analysis of Lactobacillus reuteri Strains for Short Chain Fatty Acids Production, Stability and Therapeutic Potentials in Colorectal Cancer. J Bioequiv Availab 7: $039-050$. doi:10.4172/jbb.1000212

\begin{tabular}{|c|c|c|c|c|c|c|c|c|c|}
\hline \multirow[t]{2}{*}{ Corresponding CM } & \multirow[t]{2}{*}{ SSF } & \multicolumn{3}{|c|}{ Composition (mg/L) } & \multirow[t]{2}{*}{ SSF+LA } & \multicolumn{4}{|c|}{ Composition (mg/L) } \\
\hline & & Acetate & Propionate & Butyrate & & Lactate & Acetate & Propionate & Butyrate \\
\hline L. a 314 & SSF-a & 114 & 0 & 14 & SSF-a+LA & 1948 & 114 & 0 & 14 \\
\hline L. $r 11951$ & SSF-r1 & 131 & 111 & 29 & SSF-r1+LA & 369 & 131 & 111 & 29 \\
\hline L. $r 701089$ & SSF-r8 & 43 & 38 & 0 & SSF-r8+LA & 208 & 43 & 38 & 0 \\
\hline L. $r 701359$ & SSF-r13 & 116 & 78 & 28 & SSF-r13+LA & 643 & 116 & 78 & 28 \\
\hline L. $r 702655$ & SSF-r55 & 86 & 45 & 29 & SSF-r55+LA & 233 & 86 & 45 & 29 \\
\hline L. $r 702656$ & SSF-r56 & 182 & 161 & 59 & SSF-r56+LA & 642 & 182 & 161 & 59 \\
\hline
\end{tabular}

Table 1: Composition of SCFA synthetic formulations (SSFs) containing different concentrations of acetate, propionate and butyrate (no bacteria were used), designed at the respective concentrations of naturally produced SCFAs in the CM of $L$. reuteri NCIMB $-11951,-701089,-701359,-702655$, and -702656 . Another set of SSFs was prepared by the addition of respective concentrations of lactate, same as the one produced by $L$. reuteri-CM.

NCIMB 702656, the SSFs were significantly more effective that the $L$. reuteri-CM $(p<0.05)$. For $L$. reuteri $\mathrm{NCIMB} 702655$, the $L$. reuteri$\mathrm{CM}$ had no anti-proliferative effect while the SSF did. However, for L. reuteri NCIMB 701359, SSFs showed significantly less effect that $L$. reuteri-CM. After addition of lactic acid to each SSFs, SSF-r56+LA $(24.15 \pm 1.03 \%$ of cell inhibition) and, SSF-r1+LA (19.23 $\pm 4.3 \%$ of cell inhibition) significantly reduced cancer cell growth compared with SSF-r 13+LA (9.07 $\pm 0.99 \%$ of cell inhibition, $p=0.001, p=0.26$, respectively) and SSF-r55+LA (8.32 $\pm 1.78 \%$ of cell inhibition, $p<$ $0.001, p=0.016)$. SSF-r8+LA had no effect compared with the treated or untreated cells $(p>0.05)$.

\section{Resistance of $L$. reuteri bacteria to SIF}

One of the criteria of probiotic selection is their ability to resist the harsh colonic and intestinal environment. Therefore, this experiment was designed to monitor the density and the viability of bacteria inoculated in the simulated intestinal media. As described in Fig. 6 and 7, the viability and concentration of $L$. reuteri NCIMB $-701359,-11951$, and -702656, identified in this study for their higher anti-proliferative activity, was evaluated in SIF at different time points. The data showed that our bacteria of interest demonstrated showed resistance to this environment in comparison with the other strains up to $4 \mathrm{~h}$ in SIF. No significant difference was observed between L. reuteri NCIMB 11951 (Fig. 7 (b)), L. reuteri NCIMB 701359 (Fig. 7 (d)), L. reuteri NCIMB 702656 (Fig. 7 (c)), and the control L. acidophilus ATCC 314 (94.9 \pm $0.6 \%$, Fig. 7 (a))). It was only after $8 \mathrm{~h}$ of incubation that the viability of each $L$. reuteri strain decreased, depending on its resistance to the SIF. At $8 \mathrm{~h}$ of incubation in SIF, L. reuteri NCIMB 11951 had higher viability $(121 \pm 6.4 \%, p<0.001)$ than all other bacteria: $L$. acidophilus ATCC $314(89.1 \pm 0.8 \%)$; L. reuteri NCIMB 701359 (80.5 $\pm 2.2 \%)$; and L. reuteri NCIMB $702656(69.2 \pm 1.4 \%)$. However, the viability of $L$. reuteri NCIMB 701359 was not significantly different from $L$. reuteri NCIMB 702656 after $12 \mathrm{~h}$ of incubation.

\section{L. reuteri produces lactate and SCFAs in SIF}

Following the investigation of bacterial resistance to simulated intestinal conditions, and to understand the in-vitro fermentation of probiotic bacteria in a SIF, the production of SCFAs and lactic acid was determined for L. reuteri NCIMB -701359, -11951 and -702656, as shown in Fig. 8. Results showed that lactic, acetic and propionic acids were produced at different levels in the SIF. For lactic acid production, L. reuteri $\mathrm{NCIMB} 11951(2762.9 \pm 106.6 \mathrm{mg} / \mathrm{L})$ and L. reuteri $\mathrm{NCIMB}$ $702656(2491.8 \pm 17.2 \mathrm{mg} / \mathrm{L})$ were significantly higher compared with L. acidophilus ATCC 314 ( $p<0.001$ and $p=0.003$, respectively) and $L$. reuteri NCIMB $701359(2121.3 \pm 17.3 \mathrm{mg} / \mathrm{L}, p=0.001$ and $p=0.016$, respectively). For acetic acid bio-production in SIF (Fig. 9 (a)), the $L$. reuteri NCIMB $702656(650 \pm 0.02 \mathrm{mg} / \mathrm{L})$ was significantly higher, followed by $L$. reuteri NCIMB $11951(631.2 \pm 58 \mathrm{mg} / \mathrm{L})$ and $L$. reuteri NCIMB $701359(608 \pm 3.2 \mathrm{mg} / \mathrm{L}, p=0.016$ and $p=0.01$, respectively $)$ in comparison with L. acidophilus ATCC 314 ( $p=0.003, p=0.005$ and $p$ $=0.009$, respectively). However, for the production of propionic acid in SIF (Fig. 9 (b)), L. reuteri NCIMB 11951 (760.4 $\pm 44.5 \mathrm{mg} / \mathrm{L})$ produced significantly higher amounts of propionic acid, followed by $L$. reuteri NCIMB $701359(692.3 \pm 21.5 \mathrm{mg} / \mathrm{L})$ and L. reuteri NCIMB 702656 $(595.5 \pm 0.3 \mathrm{mg} / \mathrm{L})$, when compared with $L$. acidophilus ATCC 314 $(413.1 \pm 0.1 \mathrm{mg} / \mathrm{L}, p<0.001)$. In terms of total SCFAs acid production ((Fig. 9 (c)), while L. reuteri NCIMB $701359(1300.3 \pm 27.2 \mathrm{mg} / \mathrm{L})$ was not significantly different from $L$. reuteri NCIMB 11951 (1391.6 \pm 4.8 $\mathrm{mg} / \mathrm{L}, p=0.332)$, the latter produced significantly higher amounts of total SCFAs, compared with $L$. reuteri NCIMB $702656(1245.5 \pm 0.5$ $\mathrm{mg} / \mathrm{L}, p=0.07)$ and $L$. acidophilus ATCC $314(413.1 \pm 0.1 \mathrm{mg} / \mathrm{L}, p<$ $0.001)$.

\section{Discussion}

There is a need to systematically evaluate the potential use of novel probiotic bacteria in CRC therapies. Until now, $L$. reuteri bacteria exhibited few features related to colon health by altering the levels of fecal SCFAs [30,31]. In this study, we screened and characterized five strains of $L$. reuteri bacteria according to their effects on colon cancer cell inhibition and SCFAs production. The main purpose of the study was to distinguish a strain-dependent effect of a number of $L$. reuteri bacteria in suppressing colon cancer cell growth and to depict the role of bacterial SCFAs as a mechanism, either generally or straindependently.

Reduced colonic SCFAs levels haves been reported in human populations with high CRC incidents [8]. As probiotic SCFAs, mainly acetate, propionate and butyrate, were recognized for their anti-cancer activity on colon cancer, several studies have shown that this effect acts through arrested growth, and apoptosis [32]. In particular, some studies showed restored GPR43 expression, coupled with propionate treatment that, induced an upregulation of p21 and a decrease in the levels of cyclin D3 and cyclin-dependent kinases (CDKs) 1 and 2. After propionate/butyrate treatment, and G0/G1 cell cycle arrest and activated caspases were induced, leading to increased apoptotic cell death [33]. Importantly, administration of L. reuteri strains was shown to alter the levels of fecal SCFAs in animals $[30,31]$ and in fermentation systems [10]. In addition, $L$. reuteri bacteria haves been shown to affect the colonic fermentation of fibers and to stimulate the production profile of SCFAs [34] in simulated intestinal conditions [31]. This supports our hypothesis that $L$. reuteri produces SCFAs which kills cancer cells.

Thus, the first objective was to screen a number of $L$. reuteri strains: L. reuteri NCIMB -11951, -701089, -701359, -702655, and -702656, for the concentrations of SCFAs in their CM, as well as lactic acid, as a the primary characteristic of these LAB. In this study, we reported that the $L$. reuteri bacteria were bioactive enough to produce detectable amounts of lactic acid in a cell culture conditioned media (CM) using 
Citation: Kahouli I, Malhotra M, Tomaro-Duchesneau C, Saha S, Marinescu D, et al. (2015) Screening and In-Vitro Analysis of Lactobacillus reuteri Strains for Short Chain Fatty Acids Production, Stability and Therapeutic Potentials in Colorectal Cancer. J Bioequiv Availab 7: 039-050. doi:10.4172/jbb.1000212

DMEM (Fig. 1). Later, SCFAs were quantified in the CM and the levels of acetic, propionic, and butyric acids produceds shown to be strain-dependent (Fig. 2). Moreover, we showed that L. reuteri NCIMB -11951, -701359, and -702656 produced higher concentrations of SCFAs and lactic acid compared with the other $L$. reuteri strains. It was noted that the concentrations of acetic and propionic acids measured in this study were about half the optimal doses used in the literature to induce anti-proliferative effect on Caco-2 cells [35], which predict a possible inhibitory effect of the probiotic treatments on colon cancer cells.

Very few studies showed the effect of $L$. reuteri bacteria on colon cancer cells. In some one case study, L. reuteri promoted TNF- induced apoptosis and suppressed cell proliferation and anti-apoptotic proteins by down-regulating nuclear factor- $\kappa \mathrm{B}(\mathrm{NF}-\kappa \mathrm{B})$-dependent gene products that mediate cell proliferation (Cox-2, cyclin D1) and cell survival (Bcl-2, Bcl-xL) [36]. In some cases, the identification of the anti-proliferative effect of probiotics in-vitro can, also, be measured by the effect of bacterial extracts on colon cancer cell colony formation and have shown similar results to the proliferation assay $[37,38]$. We determined that L. reuteri NCIMB -11951, -701359, and -702656 exhibited the greatest inhibition of colon cancer cell proliferation s (72 h, Fig. 3), respectively, compared to untreated cells. These observations, shown for the first time, are consistent with the findings that $\mathrm{LAB}$ and, more specifically, $L$. reuteri, may have anticancer activity induced by SCFA production in the colon which may a

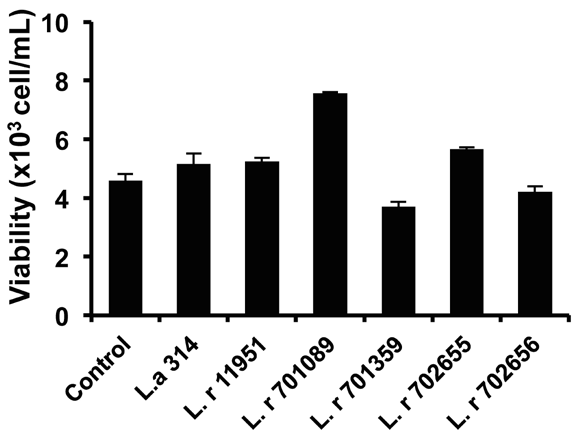

b

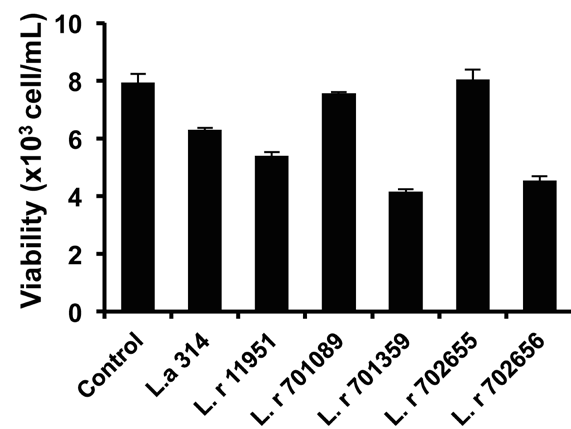

C

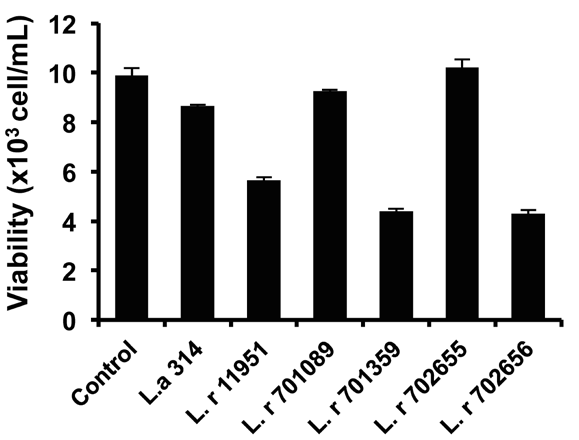

Caco-2 + CM - 24 h

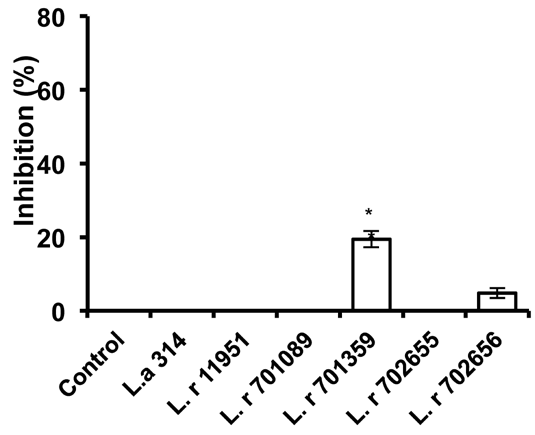

Caco-2 + CM - 48 h

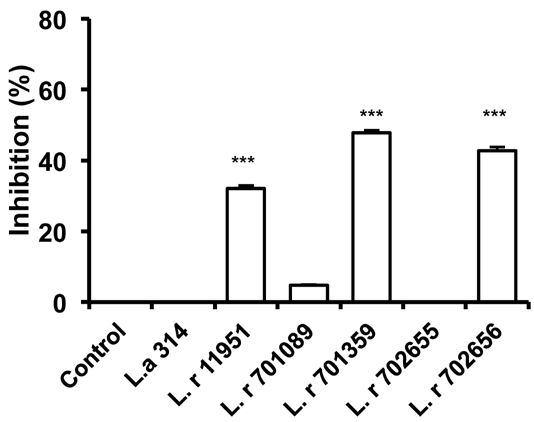

Caco-2 + CM - 72 h

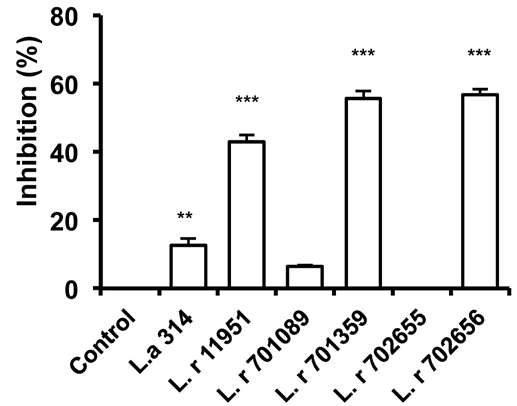

Figure 3: Screening of $L$. reuteri strains for a potential anti-proliferative effect against colon cancer cells. To investigate the anti-proliferative effect of probiotic $L$. reuteri bacteria, the cell culture conditioned medium (CM) of $L$. reuteri NCIMB $-11951,-701089,-701359,-702655$, and -702656 was used. The viability and growth inhibition of human epithelial CRC adenocarcinoma cells (Caco-2) by the $L$. reuteri-CM was measured after incubation with probiotic treatments for (a) $24 \mathrm{~h}$, (b) $48 \mathrm{~h}$ and (c) $72 \mathrm{~h}$, using ATP bioluminescence. $L$. acidophilus ATCC 314 is used as a positive control for comparative purposes. Data are presented as mean \pm SEM ( $=4$ ). ${ }^{*} p<0.05,{ }^{*} p<0.01$ and ${ }^{* * *} p<0.001$, compared with L. reuteri NCIMB 702655. 
Citation: Kahouli I, Malhotra M, Tomaro-Duchesneau C, Saha S, Marinescu D, et al. (2015) Screening and In-Vitro Analysis of Lactobacillus reuteri Strains for Short Chain Fatty Acids Production, Stability and Therapeutic Potentials in Colorectal Cancer. J Bioequiv Availab 7: 039-050. doi:10.4172/jbb.1000212

decrease tumor growth, inhibit colon cancer cell growth, and promote apoptosis [39]. It is possible that probiotic bacteria have altered colon cancer cell metabolism. Few reports have related the effect of probiotic SCFAs to the production of lactate in cancer cells [40]. Nevertheless, some studies showed that butyrate analogs such as propionate and L-lactate significantly inhibited uptake of butyrate in cancer cells [41], but they may still have a potential effect in decreasing glycolysis /lactate secretion and thus killing cancer cells [42].

As described in Fig. 4, the correlations, between the suppression of colon cancer cell growth by L. reuteri and the SCFAs, produced in probiotic CM, were analyzed. A positive correlation has been observed between the inhibition of cancer cells and the concentration of acetic acid $(\mathrm{r}=0.78, p<0.001)$, propionic acid $(\mathrm{r}=0.79, p<0.001)$, butyric acid $(\mathrm{r}=0.66, p=0.011)$ and total SCFAs $(\mathrm{r}=0.77, p<0.001)$ produced by $L$. reuteri bacteria.

To investigate this further, concentrations of pure SCFAs, both, with and without lactic acid, were prepared as different mixtures and tested on colon cancer cells (Fig. 5). These, however, showed different levels of inhibitions, which argues for the ability of naturally produced SCFAs in the CM to kill cancer cells. Surprisingly, the SCFA formulations, corresponding to $L$. reuteri strains, that inhibited the most colon cancer cell proliferation the most were SSF-r1, SSF-r13 and SSF-r56, which correspond, respectively, to L. reuteri NCIMB -11951, -701359, and -702656; that, as shown above, produced the highest levels of SCFAs and inhibited the cancer cells the most (Fig. 5). A correlation was shown between the effect of SCFA synthetic formulations and $L$. reuteri-CM on colon cancer cell proliferation $(\mathrm{r}=0.84, p=0.001)$. This suggests that the anti-proliferative effect of the CM is possibly due, in a major part, to the concentration bacterial SCFAs but the effect is not only related to the presence of SCFAs. It is important to note, that the $L$. reuteri-CM were DMEM media modified by the incubation of probiotic bacterial cells, which had changed the composition of the cell media and produced SCFAs and other bacterial products. This makes the addition of SCFAs to standard cell media, in the case of synthetic SCFA synthetic formulations just an approximate way to test the effect of SCFAs alone and may affect the evaluation of cell anti-proliferation activity versus the effect of bacterial SCFAs production. The significant difference between the inhibition by SSF+LA and probiotic-SCFAsnaturally-containing $\mathrm{CM}(p<0.001$, SCFA formulations vs CM, Fig. 5 ) is probably due to the presence of other microbial components such as CpG DNA, flagellin and lipopolysaccharide (LPS) which are, shown to inhibit tumor growth by activating pattern recognition receptors in colon epithelial cells [43]. This indicates also that the presence of other bacterial product may complement and enhance the anti-proliferative and thus the anti-carcinogenic activity of SCFAs in the bacterial extract. These findings extend our understanding of the complexity of the interactions between probiotic bacterial products and colon cells. In fact, gut mirobiota were found to produce different components (organic acids, bacteriocins, peptides, etc.) that interacts with tumor microenvironment. SCFAs were the primary components related to tumor growth in the colon, since fibers and fermentable oligosaccharides gut microbial breakdown, could result primarily in the production of SCFAs bioactive molecules: acetate, propionate, and butyrate, with a general ratio of 60:25:15. Formate, valerate, caproate, and branched-chain fatty acids (isobutyrate, 2-methylvalerate, and isovalerate, etc) are produced in low quantities from the catabolism of some branched-chain amino acids. Interestingly, studies have shown that polyunsaturated fatty acids and SCFAs mutually interact and protect against colon cancer [44].

Several criteria can be evaluated for probiotic bacteria such as safety, growth, and survival and, in the case of oral administration, the tolerance

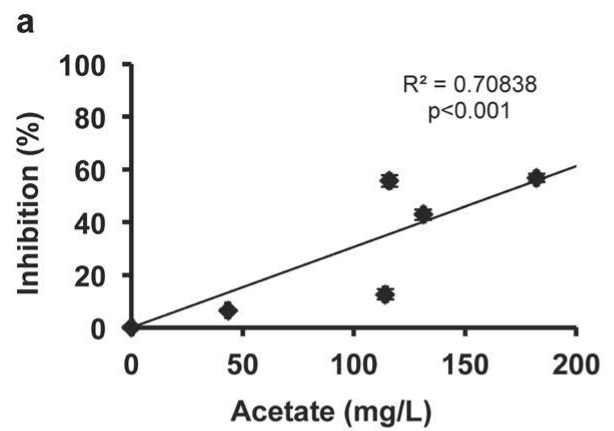

b
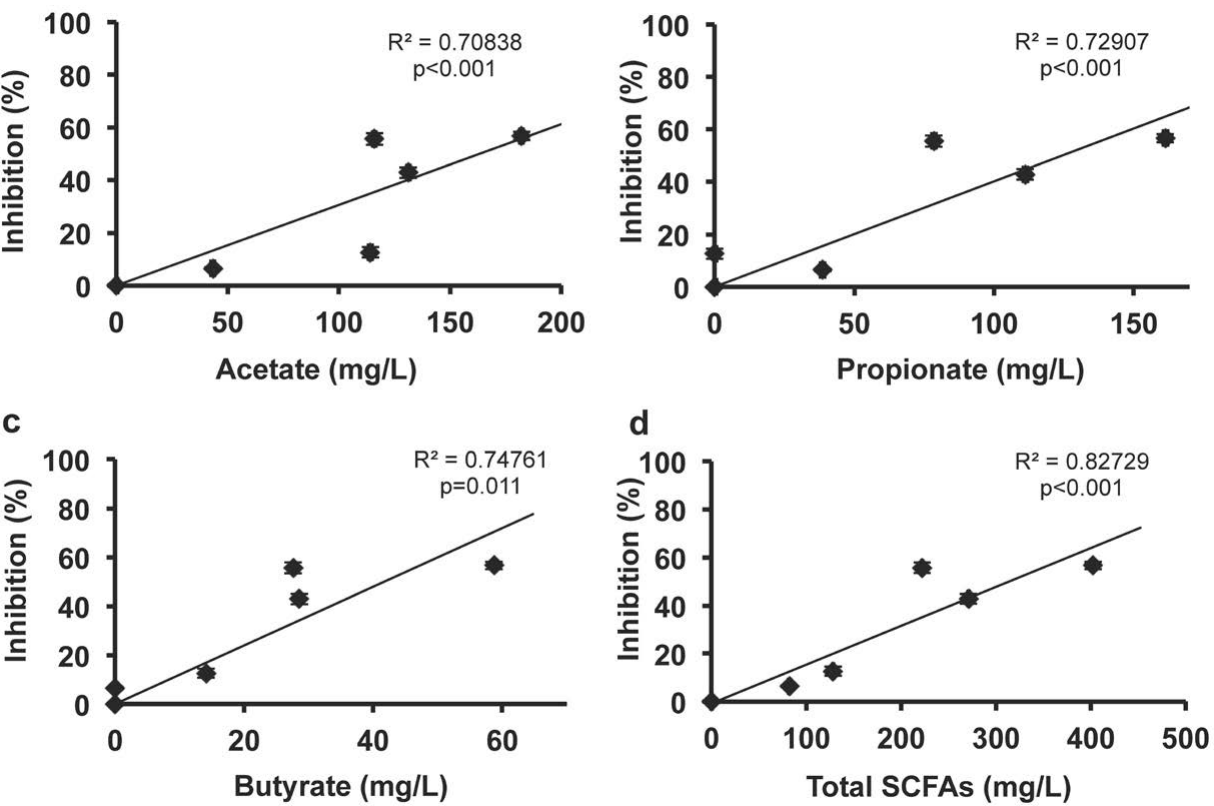

Figure 4: Correlation analysis between the production of probiotic SCFAs and the inhibition of colon cancer cell by probiotic bacteria $L$. reuteri. The correlation was determined between the concentrations of (a) acetate, (b) propionate, (c) butyrate and (d) total SCFAs in L. reuteri-CM and the inhibition of colon cancer cell growth by $L$. reuteri-CM. This test was performed to examine if $L$. reuteri-CM suppressed colon cancer cell growth due, in part, to the presence of SCFAs produced by the probiotic bacteria. The inhibition of Caco-2 proliferation by $L$. reuteri-CM was measured after $72 \mathrm{~h}$ of treatment. SCFAs were measured in the $L$. reuteri-CM used to treat Caco-2 cells. Plots represent the data of cell growth inhibition described in Fig. 2 . The lines were obtained by linear regression analysis. 
Citation: Kahouli I, Malhotra M, Tomaro-Duchesneau C, Saha S, Marinescu D, et al. (2015) Screening and In-Vitro Analysis of Lactobacillus reuteri Strains for Short Chain Fatty Acids Production, Stability and Therapeutic Potentials in Colorectal Cancer. J Bioequiv Availab 7: 039-050. doi:10.4172/jbb.1000212

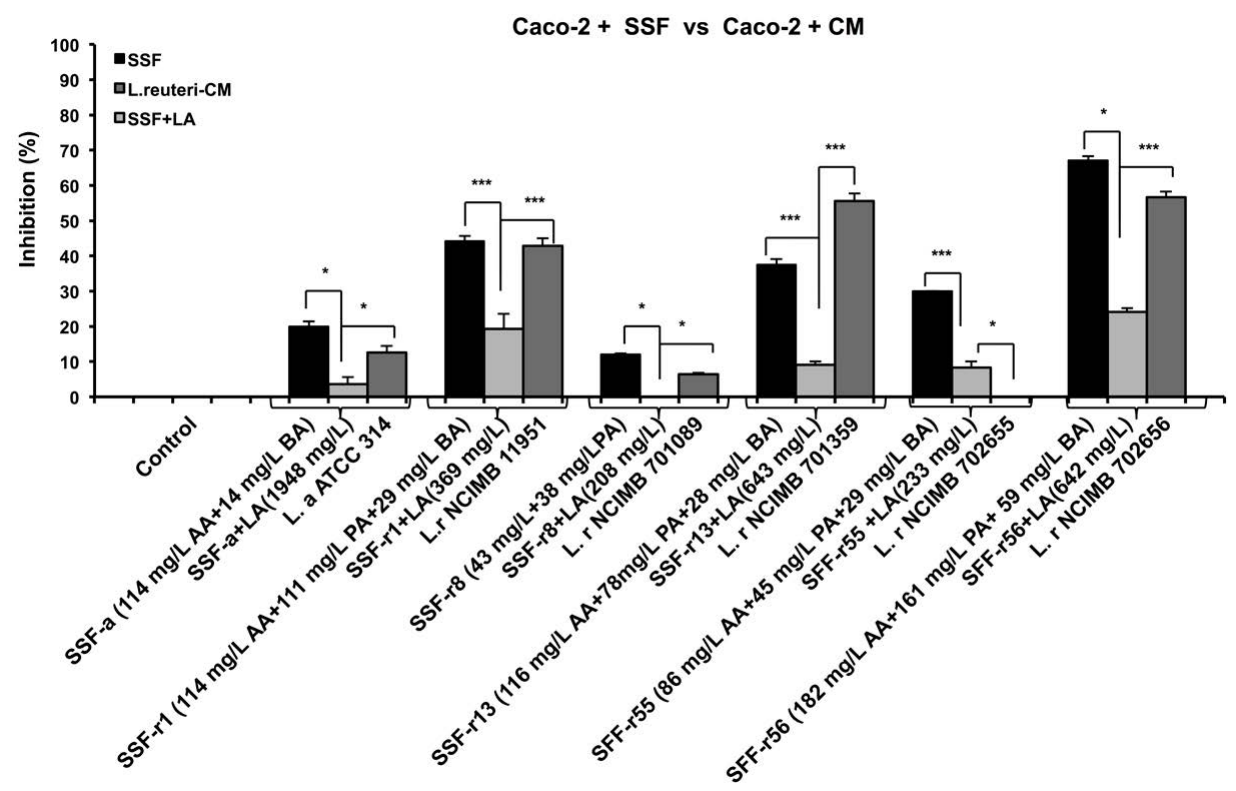

Figure 5: Comparison of the anti-proliferative effect of SCFA synthetic formulations (SSFs) with the anti-proliferative effect of $L$. reuteri-CM. This evaluation was performed to study if $L$. reuteri-CM owe, totally or partially, their effect in suppressing colon cancer cells to the levels of naturally produced SCFAs they contained? The quantities of chemical compounds in the synthetic formulations are the same as naturally produced by $L$. reuteri bacteria $(L$. reuteri NCIMB $-11951,-701089$, $-701359,-702655$, and 702656) in CM, as presented in Table 1. L. acidophilus ATCC 314 is used as a positive control and for comparative purposes. Data are represented as mean \pm SEM $(n=5) .{ }^{*} p<0.05$ and ${ }^{* \star *} p<0.001$, compared with untreated groups.

a
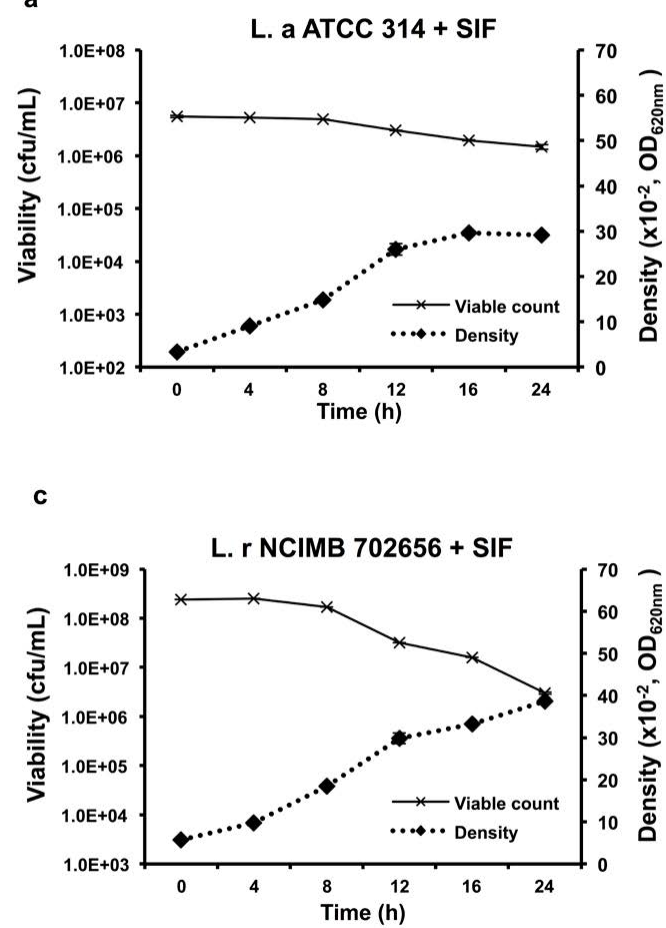

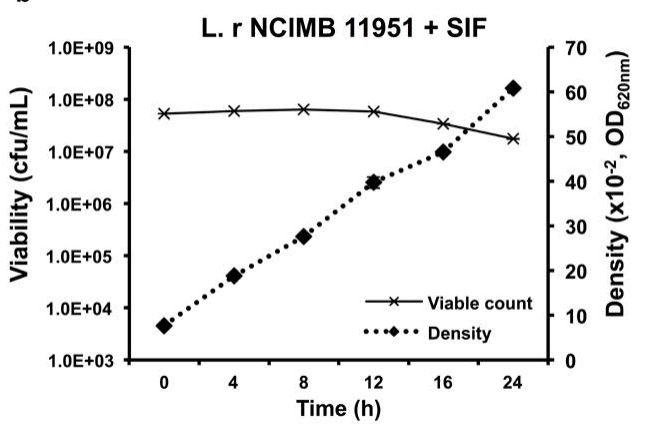

d

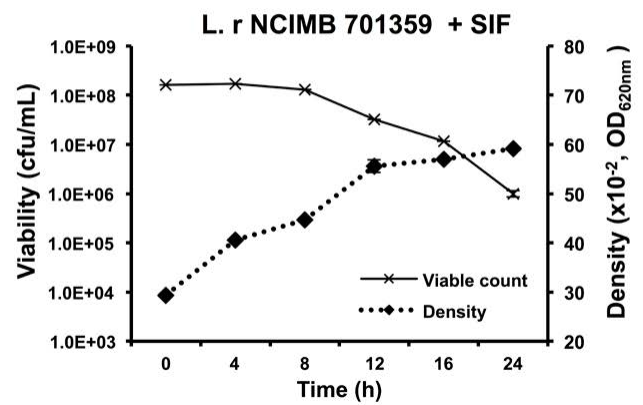

Figure 6: Bacterial cell culture characterization for $L$ reuteri strains in a simulated intestinal fluid (SIF), (pH $=6.8,24 \mathrm{~h})$. The variation in bacterial viable cell count and cell culture absorbance of (b) L. reuteri NCIMB -11951, (c) -701359 , and (d) -702656 , in addition to (a) L. acidophilus ATCC 314, was determined in micro-anaerobic conditions. The SIF used contained glucose $(5.5 \mathrm{~g} / \mathrm{L})$, yeast extract $(3.5 \mathrm{~g} / \mathrm{L})$, pancreatin $(2 \mathrm{~g} / \mathrm{L})$, oxgall $(1.5 \mathrm{~g} / \mathrm{L})$, pectin $(2 \mathrm{~g} / \mathrm{L})$, inulin $(0.54 \mathrm{~g} / \mathrm{L})$ fructooligosaccharides $(0.85 \mathrm{~g} / \mathrm{L})$, starch $(3 \mathrm{~g} / \mathrm{L})$, and monobasic potassium phosphate $\left(\mathrm{KH}_{2} \mathrm{PO}_{4}, 3.3 \mathrm{~g} / \mathrm{L}\right)$. The data is presented as mean $\pm \mathrm{SEM}(n=3)$.

of the bacterium to harsh intestinal conditions. Thus, this study also evaluated the loss of viability of $L$. reuteri bacteria in simulated human intestinal conditions and the preservation of fermentative ability, as determined by the concentration of SCFAs produced in SIF. Of note, the best probiotic candidates, in terms of potential in-vitro anti-cancer activity, L. reuteri NCIMB -701359, -11951, and -702656, were selected 
Citation: Kahouli I, Malhotra M, Tomaro-Duchesneau C, Saha S, Marinescu D, et al. (2015) Screening and In-Vitro Analysis of Lactobacillus reuteri Strains for Short Chain Fatty Acids Production, Stability and Therapeutic Potentials in Colorectal Cancer. J Bioequiv Availab 7: 039-050. doi:10.4172/jbb.1000212

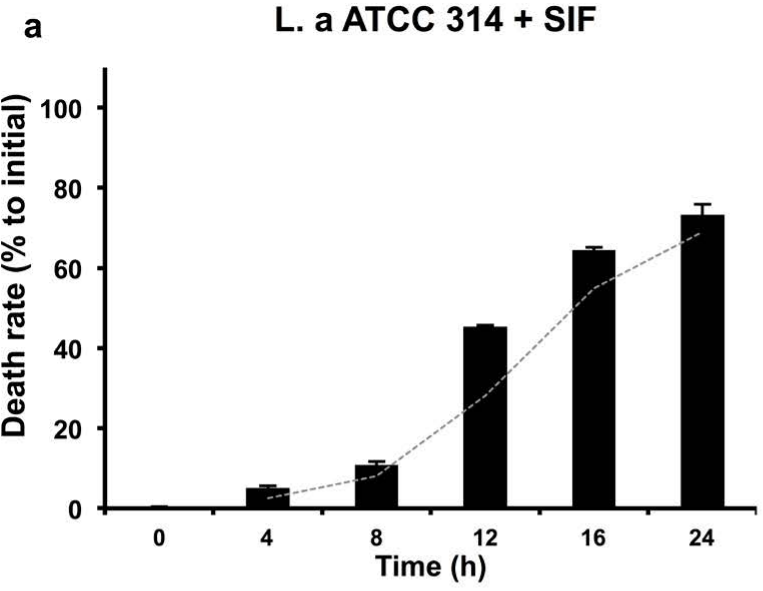

C

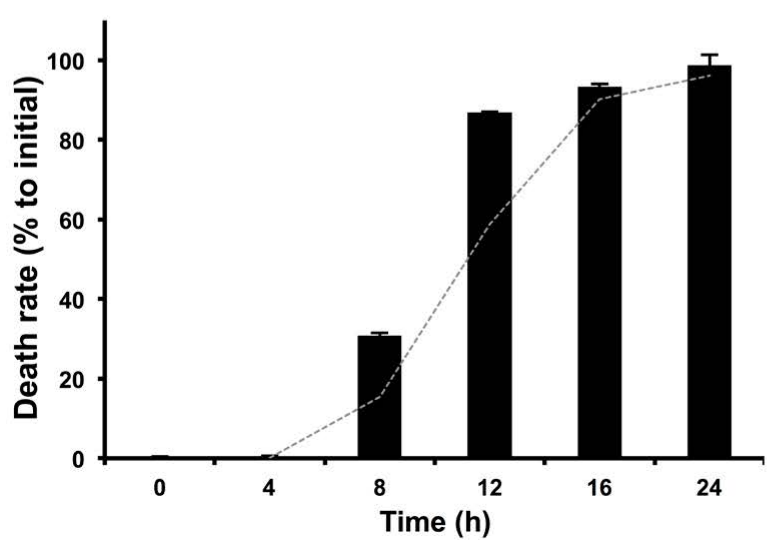

b

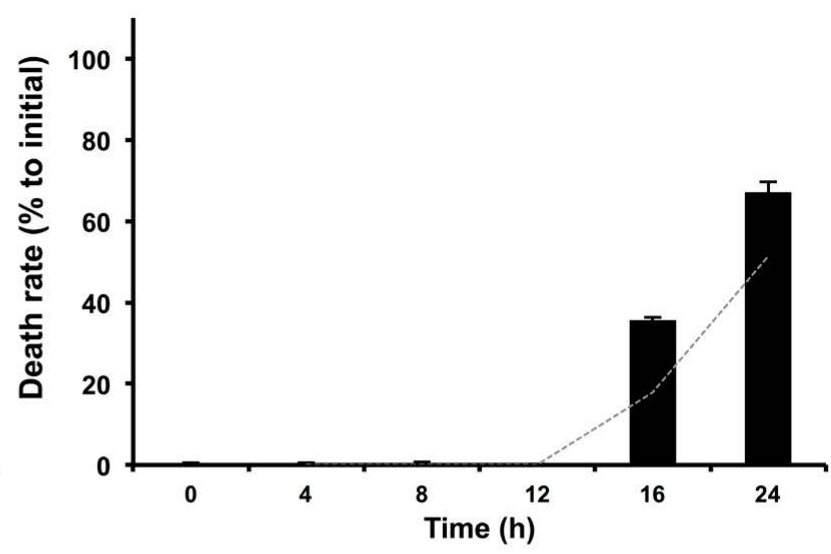

d

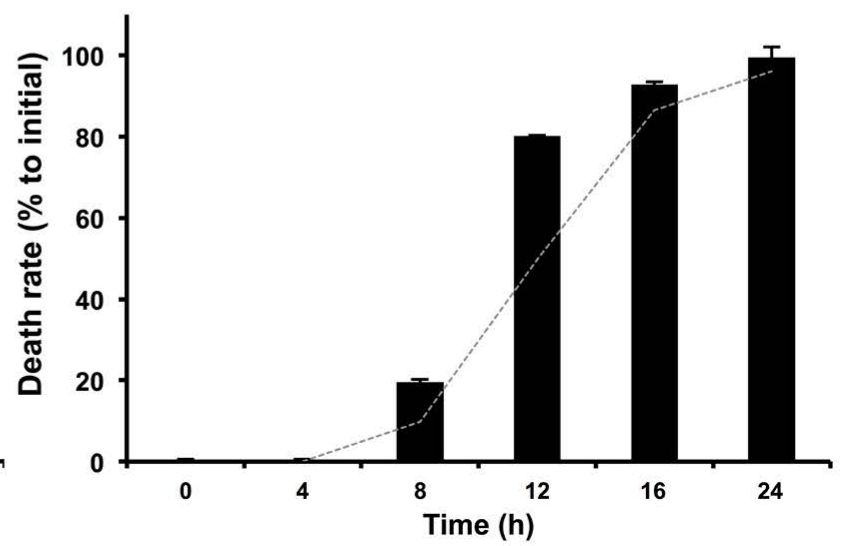

Figure 7: Death rate of $L$ reuteri bacteria in a simulated intestinal fluid (SIF) (pH = 6.8, 24 h). SIF was a mixture of glucose (5.5 g/L), yeast extract (3.5 g/L), pancreatin $(2 \mathrm{~g} / \mathrm{L})$, oxgall $(1.5 \mathrm{~g} / \mathrm{L})$, pectin $(2 \mathrm{~g} / \mathrm{L})$, inulin $(0.54 \mathrm{~g} / \mathrm{L})$ fructooligosaccharides $(0.85 \mathrm{~g} / \mathrm{L})$, starch $(3 \mathrm{~g} / \mathrm{L})$, and monobasic potassium phosphate $\left(\mathrm{KH} \mathrm{PO}_{4}, 3.3\right.$ $\mathrm{g} / \mathrm{L}$ ). The percentage of dead bacterial cell compared to initial count of $L$. reuteri NCIMB (b) -11951 , (c) -701359 , and (d) -702656 in addition to (a) $L$. acidophilus ATCC 314 , was determined in micro-anaerobic conditions. The data is presented as mean \pm SEM $(n=3)$.

for the characterization of their bacterial cultures (Fig. 6) and survival in SIF (Fig. 7). Interestingly, all strains showed similar resistance and survived bile exposure of $4 \mathrm{~h}$. A number of studies have shown that $L$. reuteri have resistance to gut conditions; however, this feature varied according to the availability of glucose and other nutrients in the gut. $L$. reuteri tolerance to intestinal conditions was evaluated, mainly, for a maximum of $4 \mathrm{~h}$ of exposure while being compared with other probiotic bacteria [45]. In an animal-based study, probiotic bacteria was administrated at $10^{10} \mathrm{cfu}$, reached the intestine at 6-8 log, similarly to our strains, and persisted for days [46]. Another study, screening the resistance of $L$. reuteri bacteria to acidic conditions and bile acid, tested several strains for 2-3 h of exposure to different bile acid concentrations and showed a survival rate of between $35 \%$ and $70 \%$ after just $3 \mathrm{~h}$, with a decrease of up to $\log 5$. In addition, only $73 \%$ of the 35 screened $L$. reuteri strains were not able to survive up to $3 \mathrm{~h}$ [47]. In our case, both L. reuteri NCIMB -702656 (Fig. 7 (c)) and -701359 (Fig. 7 (d)), showed similar resistance to SIF in early incubation in comparison with $L$. reuteri NCIMB 11951 (Fig. 7 (b)) and L. acidophilus ATCC 314 (Fig. 7 (a)). This may answer the question: Are these bacteria suitable as an effective chemopreventive agent against CRC development, since they have the same survival as other bacteria for $4 \mathrm{~h}$ in SIF? Furthermore, even after $24 \mathrm{~h}$, they are still viable at $\log 6$, which strongly suggests they are viable in the intestinal environment [48].

Even though both L. reuteri NCIMB -702656 and -701359 were less viable in comparison with $L$. reuteri NCIMB 11951 and $L$. acidophilus ATCC 314 at $24 \mathrm{~h}$ in SIF, they were able to produce the same concentrations of SCFAs, which shows they may have superior activity in the gut.

In fact, $L$. reuteri strains appeared to be active and resistant enough in the SIF to produce considerable amounts of lactic, acetic and propionic acids, which was higher than what was produced in the CM $(p<0.001)$. This suggests that a higher beneficial effect may be observed in the intestinal environment. At first, the data suggested that, in SIF, L. reuteri NCIMB and L. reuteri NCIMB 702656 produced significantly more lactic acid than $L$. reuteri $\operatorname{NCIMB} 701359(p=0.01$ and $p=0.016$, respectively, Fig. 8). However, in terms of bacterial acetic and propionic acid production in SIF, no significant difference among these three strains was observed. Remarkably, the levels of total SCFAs produced by $L$. reuteri NCIMB 11951 ( $p=0.331$ ) with significant higher survival in the SIF $(p<0.001)$, was non significant with $L$. reuteri, NCIMB $702656(p=0.07)$ and L. reuteri $\operatorname{NCIMB~} 701359(p=$ 
Citation: Kahouli I, Malhotra M, Tomaro-Duchesneau C, Saha S, Marinescu D, et al. (2015) Screening and In-Vitro Analysis of Lactobacillus reuteri Strains for Short Chain Fatty Acids Production, Stability and Therapeutic Potentials in Colorectal Cancer. J Bioequiv Availab 7: 039-050. doi:10.4172/jbb.1000212

Lactate - SIF

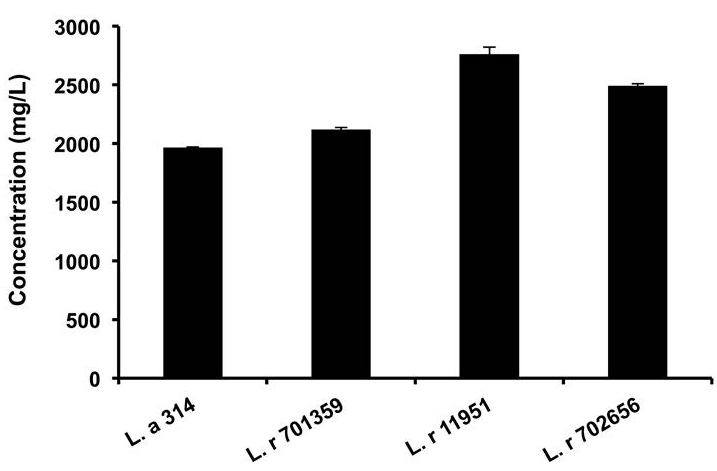

Figure 8: Ability of $L$, reuteri to produce lactic acid in simulated intestina conditions. The concentrations of lactic acid produced by $L$. reuteri NCIMB $-11951,-701359$ and -702656 in $\mathrm{SIF}\left(\mathrm{pH}=6.8,24 \mathrm{~h}, 37^{\circ} \mathrm{C}, 5 \% \mathrm{CO}_{2}\right)$ were identified and compared to $L$. acidophilus ATCC 314. Data are presented as mean $\pm \operatorname{SEM}(n=3)$.

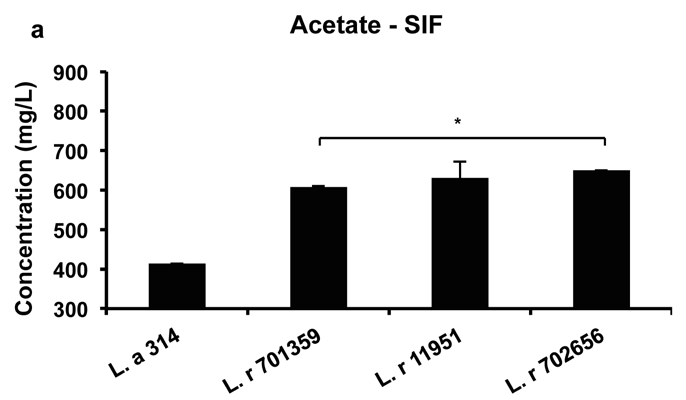

b

Propionate - SIF

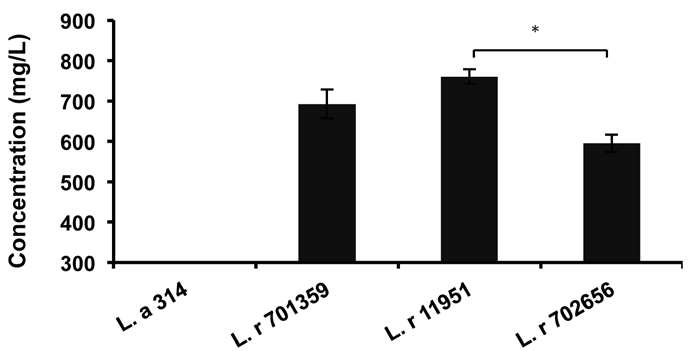

Total SCFAs - SIF

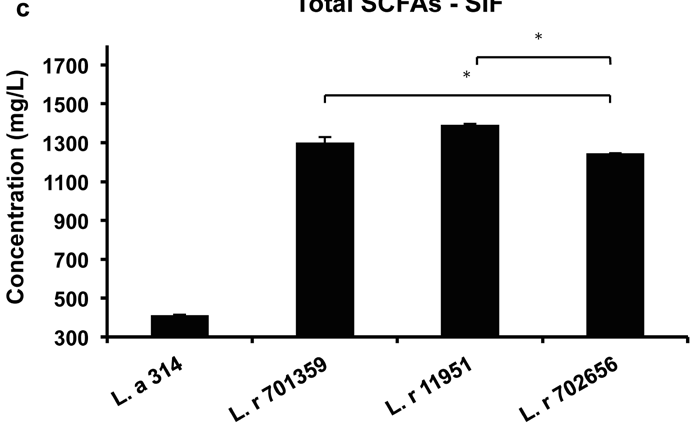

Figure 9: Quantification of the SCFAs produced by L. reuteri in simulated intestinal conditions. To show that $L$. reuteri NCIMB $-11951,-701359$ and -702656 are still able to produce significant amounts SCFAs, in an intestinal environment, and induce potential inhibitory effects against colon cancer cells in the gut, the concentrations of (a) acetate, (b) propionate, butyrate (ND) and (c) total SCFAs produced by L. reuteri NCIMB $-11951,-701359$, and -702656 in SIF ( $\left.\mathrm{pH}=6.8,24 \mathrm{~h}, 37^{\circ} \mathrm{C}, 5 \% \mathrm{CO}_{2}\right)$ were identified by HPLC. L. acidophilus ATCC 314 is used as a control. Data are presented as mean $\pm \operatorname{SEM}(n=3){ }^{*} p$ $<0.05$ ND: not detected.
0.332). This result demonstrated that the L. reuteri NCIMB -702656 and -701359 are the best potential strains for the production of SCFAs in simulated intestinal conditions (Fig. 9). The results also indicated that L. reuteri NCIMB - 701359 and -702656 have the potential to effectively produce more produce SCFAs in the colonic environment than $L$. reuteri NCIMB 11951. In comparison with other studies using different media, this study found propionic acid produced in SIF to be double the amount produced by different $L$. reuteri isolates, whereas acetic and lactic acids levels were relatively low [49]. This study confirmed similar research which demonstrated $L$. reuteri to have the ability to increase SCFAs production and fermentation in human simulated digestive fluids [15]. It is not unlikely that $L$. reuteri bacteria will favor cell death in tumor cells via local production of colonic SCFAs, making it an interesting candidate for biotherapeutic application in colon health and cancer prevention

\section{Conclusion}

In this study, we determined whether L. reuteri bacteria may produce SCFAs to inhibit colon cancer cell proliferation. For this purpose, five strains of $L$. reuteri (L. reuteri NCIMB -11951, -701089, -701359, -702655, and -702656), were selected for their tolerance to intestinal stress, and shown to produce SCFAs in CM or SIF and suppress colon cancer cell growth. This study was the first to compare the anti-proliferative effect of $L$. reuteri probiotic bacterial strains invitro, while evaluating a potential connection with SCFAs.

Together, our findings identified a significant impact of $L$. reuteri NCIMB - 701359 and - 702656 in inhibiting colon cancer cell growth that was, related to the bacterial production of SCFAs. These strains also showed a significant efficiency in producing SCFAs in intestinal conditions. Undoubtedly, L. reuteri bacteria showed a potential anti-cancer effect and the ability to produce anti-carcinogenic active compounds, thus indicating its potential biotherapeutic effect in CRC.

\section{Acknowledgements}

The authors would like to acknowledge a Canadian Institute of Health Research (CIHR) grant (MPO 64308) and grants from Micropharma Limited to Dr. Satya Prakash, a Fonds de Recherche du Québec-Santé (FRSQ) Doctoral Award and a Faculty of Medicine George G. Harris Fellowship to Imen Kahouli and Meenakshi Malhotra. We, also, thank the analytical laboratory technicians of the Department of Chemical Engineering (McGill University), Andrew Golsztajn and Ranjan Roy for their help with the analysis.

\section{References}

1. Zhi-Hua L, Mei-Jin H, Xing-Wei Z, Lei W, Nan-Qi H (2013) The effects of perioperative probiotic treatment on serum zonulin concentration and subsequent postoperative infectious complications after colorectal cancer surgery: a double-center and double-blind randomized clinical trial. Am J Clin Nutr 97: 117-126.

2. Kahouli I, Tomaro-Duchesneau C, Prakash S (2013) Probiotics in colorectal cancer (CRC) with emphasis on mechanisms of action and current perspectives. J Med Microbiol 62: 1107-1123.

3. Din FVN, Theodoratou E, Farrington SM, Tenesa A, Barnetson RA (2010) Effect of aspirin and NSAIDs on risk and survival from colorectal cancer. Gut 59: $1670-1679$.

4. Bartik L, Whitfield GK, Kaczmarska M, Lowmiller CL, Moffet EW (2010) Curcumin: a novel nutritionally derived ligand of the vitamin $D$ receptor with implications for colon cancer chemoprevention. J Nutr Biochem 21: 1153-1161

5. Sanders ME, Guarner F, Guerrant R, Holt PR, Quigley EMM (2013) An update on the use and investigation of probiotics in health and disease. Gut 62: 787796

6. Kanauchi O, Mitsuyama K, Andoh A (2013) The new prophylactic strategy for colitic cancer in inflammatory bowel disease by modulating microbiota. Scand J Gastroenterol 48: 387-400. 
Citation: Kahouli I, Malhotra M, Tomaro-Duchesneau C, Saha S, Marinescu D, et al. (2015) Screening and In-Vitro Analysis of Lactobacillus reuteri Strains for Short Chain Fatty Acids Production, Stability and Therapeutic Potentials in Colorectal Cancer. J Bioequiv Availab 7: 039-050. doi:10.4172/jbb.1000212

7. Rafter J (2011) 77 INVITED Probiotics and Colon Cancer Prevention. Eur J Cancer 47: S21.

8. Ou J, DeLany JP, Zhang M, Sharma S, O'Keefe SJD (2012) Association Between Low Colonic Short-Chain Fatty Acids and High Bile Acids in High Colon Cancer Risk Populations. Nutrition and Cancer 64: 34-40

9. Thirabunyanon M, Boonprasom P, Niamsup P (2009) Probiotic potential of lactic acid bacteria isolated from fermented dairy milks on antiproliferation of colon cancer cells. Biotechnol Lett 31: 571-576.

10. Altonsy MO, Andrews SC, Tuohy KM (2010) Differential induction of apoptosis in human colonic carcinoma cells (Caco-2) by Atopobium, and commensal, probiotic and enteropathogenic bacteria: Mediation by the mitochondrial pathway. Int J Food Microbiol 137: 190-203.

11. Lee DK, Jang S, Kim MJ, Kim JH, Chung MJ, et al. (2008) Anti-proliferative effects of Bifidobacterium adolescentis SPM0212 extract on human colon cancer cell lines. BMC cancer 8: 310.

12. Coakley M, Ross RP, Nordgren M, Fitzgerald G, Devery R, et al. (2003) Conjugated linoleic acid biosynthesis by human-derived Bifidobacterium species. J Appl Microbiol 94: 138-145.

13. Ross RP, Stanton C, Zelder O (2008) Conjugated linoleic acid isomerase and a process for the production of conjugated linoleic acid. EP Patent 1399: 569

14. Sieber R, Collomb M, Aeschlimann A, Jelen P, Eyer H (2004) Impact of microbial cultures on conjugated linoleic acid in dairy products-a review. Int Dairy J 14: 1-15

15. O'Shea EF, Gardiner GE, O'Connor PM, Mills S, Ross RP, et al. (2009) Characterization of enterocin-and salivaricin-producing lactic acid bacteria from the mammalian gastrointestinal tract. FEMS microbiology letters 291: 24-34.

16. Talarico TL, Casas IA, Chung TC, Dobrogosz WJ (1988) Production and Isolation of Reuterin, a Growth Inhibitor Produced by Lactobacillus reuteri. Antimicrob Agents Chemother 32: 1854-1858.

17. Oliva S, Di Nardo G, Ferrari F, Mallardo S, Rossi P, et al. (2012) Randomised clinical trial: the effectiveness of Lactobacillus reuteri ATCC 55730 rectal enema in children with active distal ulcerative colitis. Aliment Pharmacol Ther 35: $327-334$

18. Coccorullo P, Strisciuglio C, Martinelli M, Miele E, Greco L (2010) Lactobacillus reuteri (DSM 17938) in Infants with Functional Chronic Constipation: A DoubleBlind, Randomized, Placebo-Controlled Study. J Pediatr 157: 598-602.

19. Francavilla R, Lionetti E, Castellaneta S, Ciruzzi F, Indrio F (2012) Randomised Clinical Trial: Lactobacillus reuteri DSM 17938 vs. Placebo in Children With Acute Diarrhoea-a double-blind study. Aliment Pharmacol Ther 36: 363-369.

20. Dicksved J, Schreiber O, Willing B, Petersson J, Rang S (2012) Lactobacillus reuteri Maintains a Functional Mucosal Barrier during DSS Treatment Despite Mucus LayerDysfunction. PLoS ONE 7: e46399.

21. Wang B, Mao YK, Diorio C, Wang L, Huizinga JD, et al. (2010) Lactobacillus reuteri ingestion and IKCa channel blockade have similar effects on rat colon motility and myenteric neurones. Neurogastroenterol Motil 22: 98-e33.

22. Fasseas MK, Fasseas C, Mountzouris KC, Syntichaki P (2013) Effects of Lactobacillus salivarius, Lactobacillus reuteri, and Pediococcus acidilactici on the nematode Caenorhabditis elegans include possible antitumor activity. App Microbiol Biotechnol 97: 2109-2118.

23. Dicks LMT, Botes M (2010) Probiotic lactic acid bacteria in the gastro-intestina tract: health benefits, safety and mode of action. Beneficial Microbes 1: 11-29.

24. Grabig A, Paclik D, Guzy C, Dankof A, Baumgart DC (2006) Escherichia coli Strain Nissle 1917 Ameliorates Experimental Colitis via Toll-Like Receptor 2and Toll-Like Receptor 4-Dependent Pathways. Infect Immun 74: 4075-4082.

25. Younghoon KY, Whang JY, Whang KY, OH S, Kim SH (2008) Characterization of the Cholesterol-Reducing Activity in a Cell-Free Supernatant of Lactobacillus acidophilus ATCC 43121. Biosci Biotechnol Biochem 72: 1483-1490.

26. Liong, MT, Shah NP (2005) Optimization of cholesterol removal, growth and fermentation patterns of Lactobacillus acidophilus ATCC 4962 in the presence of mannitol, fructo-oligosaccharide and inulin: a response surface methodology approach. J Appl Microbiol 98: 1115-1126.

27. Dubey UK, Mistry VV (1996) Effect of bifidogenic factors on growth characteristics of bifidobacteria in infant formulas. J Dairy Sci 79: 1156-1163.

28. Andreotti PE, Cree IA, Kurbacher CM, Hartmann DM, Linder D, et al. (1995)
Chemosensitivity testing of human tumors using a microplate adenosine triphosphate luminescence assay: clinical correlation for cisplatin resistance of ovarian carcinoma. Cancer Research 55: 5276-5282.

29. Zhao Q, Mutukumira A, Lee SJ, Maddox I, Shu Q (2012) Functional properties of free and encapsulated Lactobacillus reuteri DPC16 during and after passage through a simulated gastrointestinal tract. World J Microb Biot 28: 61-70.

30. Peran L, Sierra S, Comalada M, Lara-Villoslada F, Bailon E (2007) A comparative study of the preventative effects exerted by two probiotics, Lactobacillus reuter and Lactobacillus fermentum, in the trinitrobenzenesulfonic acid model of rat colitis. Br J Nutr 97: 96-103.

31. Tsukahara T, Koyama H, Okada M, Ushida K (2002) Stimulation of Butyrate Production by Gluconic Acid in Batch Culture of Pig Cecal Digesta and Identification of Butyrate-Producing Bacteria. J Nut 132: 2229-2234.

32. Tang $Y$, Chen $Y$, Jiang $H$, Nie $D$ (2011) The role of short-chain fatty acids in orchestrating two types of programmed cell death in colon cancer. Autophagy 7: 235-237.

33. Tang $Y$, Chen $Y$, Jiang H, Robbins GT, Nie D (2011) G-protein-coupled receptor for short-chain fatty acids suppresses colon cancer. Int J Cancer 128: 847-856.

34. Jiang T, Savaiano DA (1997) Modification of colonic fermentation by bifidobacteria and $\mathrm{pH}$ in vitro (impact on lactose metabolism, short-chain fatty acid, and lactate production). Digestive diseases and sciences 42: 2370-2377.

35. Basson MD, Emenaker NJ, Hong F (1998) Differential modulation of human (Caco-2) colon cancer cell line phenotype by short chain fatty acids in Proceedings of the Society for Experimental Biology and Medicine. Society fo Experimental Biology and Medicine. Royal Society of Medicine, (New York, NY

36. Iyer C, Kosters A, Sethi G, Kunnumakkara AB, Aggarwal BB, et al. (2008) Probiotic Lactobacillus reuteri promotes TNF-induced apoptosis in human myeloid leukemia-derived cells by modulation of NF-KB and MAPK signalling. Cellular microbiology 10: 1442-1452.

37. Ohigashi S, Sudo K, Kobayashi D, Takahashi O, Takahashi T, et al. (2013) Changes of the intestinal microbiota, short chain fatty acids, and fecal $\mathrm{pH}$ in patients with colorectal cancer. Digestive diseases and sciences 58: 17171726

38. Chen X, Fruehauf J, Goldsmith JD, Xu H, Katchar KK, et I. (2009). < i> Saccharomyces boulardii</i $>$ Inhibits EGF Receptor Signaling and Intestinal Tumor Growth in< i> Apcmin</i> Mice. Gastroenterology 137: 914-923.

39. Ma EL, Choi YJ, Choi J, Pothoulakis C, Rhee SH, et al. (2010) The anticance effect of probiotic Bacillus polyfermenticus on human colon cancer cells is mediated through ErbB2 and ErbB3 inhibition. International Journal of Cancer 127: $780-790$.

40. Vander Heiden MG, Cantley LC, Thompson CB (2009) Understanding the Warburg effect: the metabolic requirements of cell proliferation. Science: 324 1029-1033.

41. Hadjiagapiou C, Schmidt L, Dudeja PK, Layden TJ, Ramaswamy K (2000) Mechanism (s) of butyrate transport in Caco-2 cells: role of monocarboxylate transporter 1. Am J Physiol Gastrointest Liver Physiol 279: G775-G780.

42. Xu RH, Pelicano H, Zhou Y, Carew JS, Feng L, et al. (2005) Inhibition of glycolysis in cancer cells: a novel strategy to overcome drug resistance associated with mitochondrial respiratory defect and hypoxia. Cancer research, 65: 613-621.

43. Jin B, Sun T, Yu XH, Yang YX, Yeo AE (2012) The effects of TLR activation on T-cell development and differentiation. Clinical and Developmental Immunology $1-32$.

44. Kumar M, Nagpal R, Verma V, Kumar A, Kaur N, et al. (2013) Probiotic metabolites as epigenetic targets in the prevention of colon cancer. Nutrition reviews $71: 23-34$.

45. Charalampopoulos D, Pandiella SS, Webb C (2003) Evaluation of the effect of malt, wheat and barley extracts on the viability of potentially probiotic lactic acid bacteria under acidic conditions. International Journal of Food Microbiology 82 133-141.

46. De Angelis M, Siragusa S, Caputo L, Ragni A, Burzigotti R et al. (2007) Survival and persistence of Lactobacillus plantarum 4.1 and Lactobacillus reuteri $3 S 7$ in the gastrointestinal tract of pigs. Vet Microbiol 123: 133-144.

47. Singh TP, Kaur G, Malik RK, Schillinger U, Guigas C, et al. 
Citation: Kahouli I, Malhotra M, Tomaro-Duchesneau C, Saha S, Marinescu D, et al. (2015) Screening and In-Vitro Analysis of Lactobacillus reuteri Strains for Short Chain Fatty Acids Production, Stability and Therapeutic Potentials in Colorectal Cancer. J Bioequiv Availab 7: 039-050. doi:10.4172/jbb.1000212

Characterization of intestinal Lactobacillus reuteri strains as potential probiotics. Probiotics Antimicrob Proteins 4: 47-58.

48. Dommels YEM, Kemperman RA, Zebregs YEMP, Draaisma RB, Jol A (2009) Survival of Lactobacillus reuteri DSM 17938 and Lactobacillus rhamnosus GG in the Human Gastrointestinal Tract with Daily Consumption of a Low-Fat Probiotic Spread. Appl Environ Microbiol 75: 6198-6204.
49. Zhao Q, Maddox IS, Mutukumira A, Lee SJ, Shu Q (2012) The effect of cell immobilization on the antibacterial activity of Lactobacillus reuteri DPC16 cells during passage through a simulated gastrointestinal tract system. World J Microb Biot 28: 3025-3037. 